\title{
VISG
}

\section{Volcanic and Magmatic Studies Group Members Survey 2020}

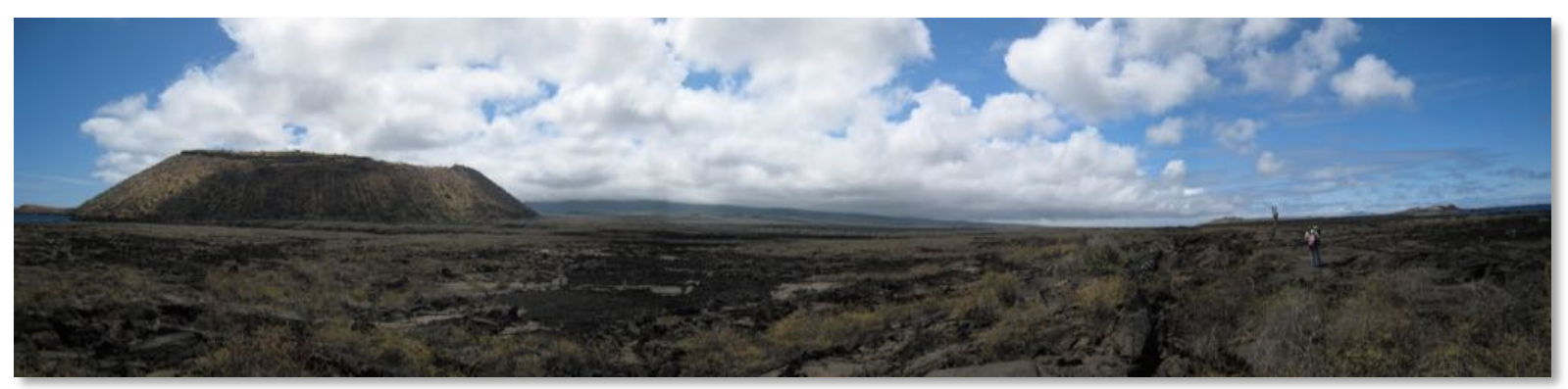

The Volcanic \& Magmatic Studies Group (VMSG) is a joint Special Interest Group of the Geological Society of London and Mineralogical Society. In January 2020 we conducted an online questionnaire to establish if (and how) VMSG fulfils its mission to serve the volcanology, petrology and geochemistry community.

The survey was distributed via the VMSG mailing list, publicised at the VMSG annual meeting and shared over social media. Our aim was to learn about our community as it exists in 2020, and we welcomed candid views as to how we might modify VMSG activities to ensure we are a welcoming and inclusive organisation for all. The VMSG does not charge membership fees and keeps no records of individual member details. Therefore, this survey includes responses from those who self-identify as members of the VMSG community.

A total of 110 responses were received (for context, up to 200 members attend our annual meetings and we have approximately 1000 subscribers to our email list). Each completed survey was anonymous and confidential, and participants were notified that all information will be handled in compliance with the General Data Protection Regulations 2018. The following report contains statistics from the survey and a summary of comments that we have grouped into themes (not verbatim). We use a star to indicate high-frequency comments from participants ( ${ }^{* *}=$ very frequent, $*$ = frequent). We conclude with some overall thoughts on what the survey results mean for the future priorities of VMSG.

Sally A. Gibson (Chair of VMSG) and Janine L. Kavanagh (Honorable Secretary)
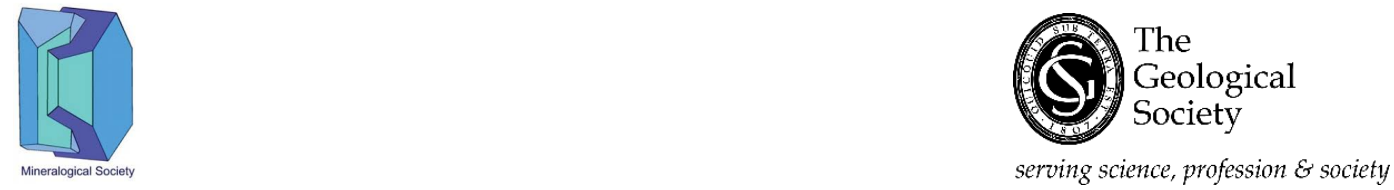

[This document is a preprint submitted to EarthArXiv. It has not undergone peer-review] 


\section{Table of Contents}

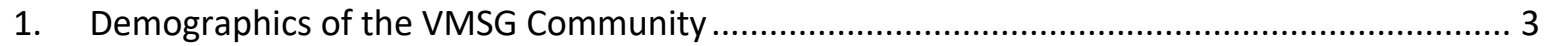

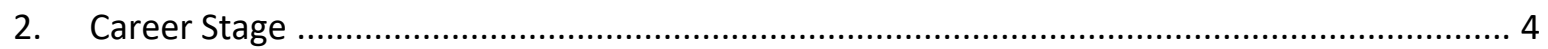

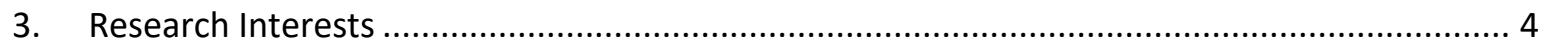

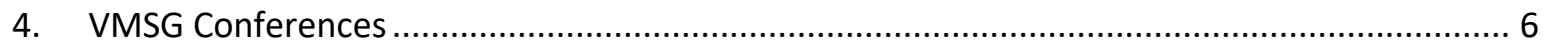

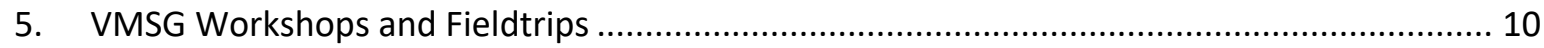

6. VMSG Student Bursaries and Fieldwork Grants ................................................ 11

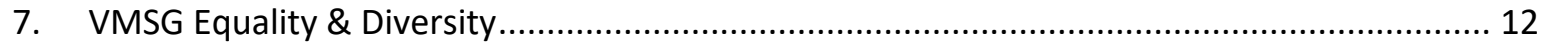

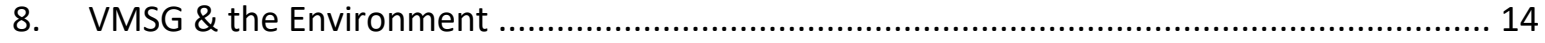

9. VMSG Communications \& Making VMSG Work for you............................................ 15

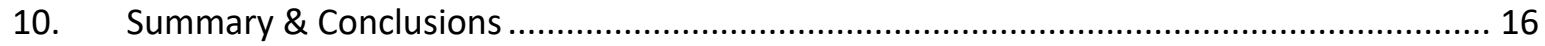




\section{Demographics of the VMSG Community}

Information on the demographics of VMSG members is essential to enable us to ensure we appropriately hear, represent and support the views of our whole community. The survey shows that the VMSG community is diverse in terms of gender, sexual orientation and place of residence. From those who answered the survey, $60 \%$ identified as male and $38 \%$ identified as female, $85 \%$ identified as heterosexual whereas gay, bisexual or asexual collectively accounted for $8 \%$ of responses. Our members are largely resident in the UK (81\%), followed by Europe (14\%), North America (4\%) and Asia (1\%).

\subsection{How would you describe your gender? (105 responses)}

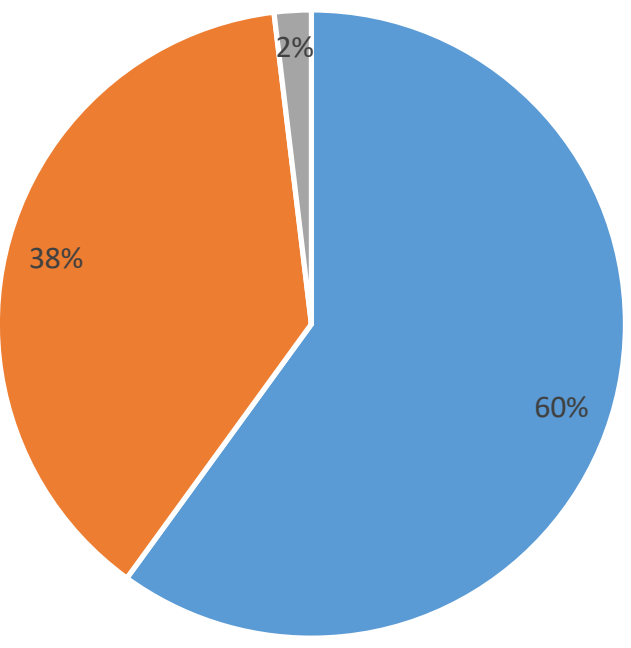

- Male (including transgender men) - Female (including transgender women) $\quad$ Prefer not to say

\subsection{Which sexual orientation best represents you? (100 responses)}

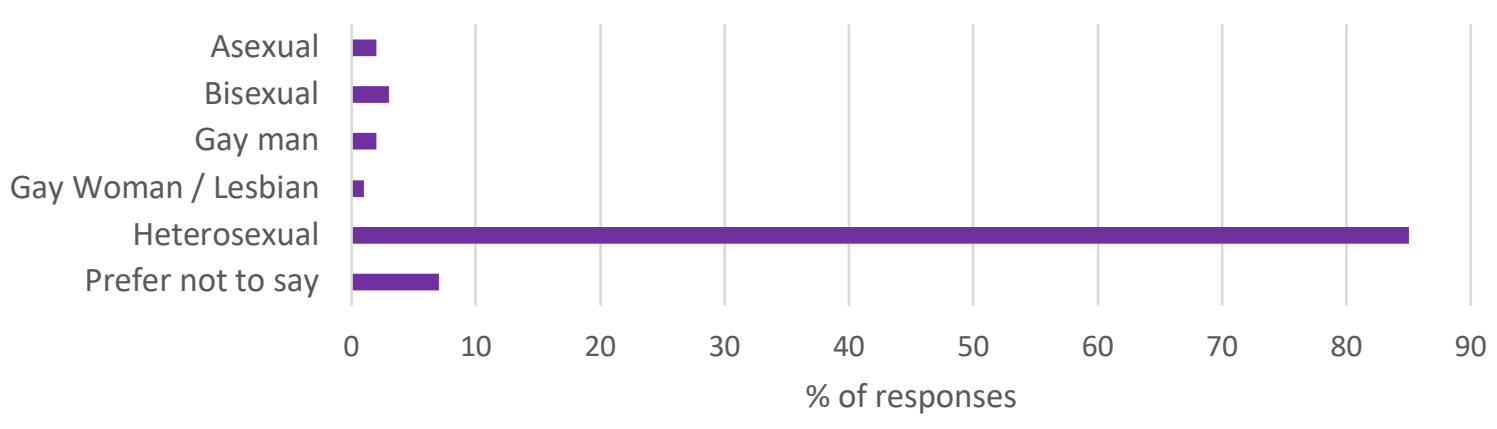

\subsection{Please select your place of residence (104 responses)}

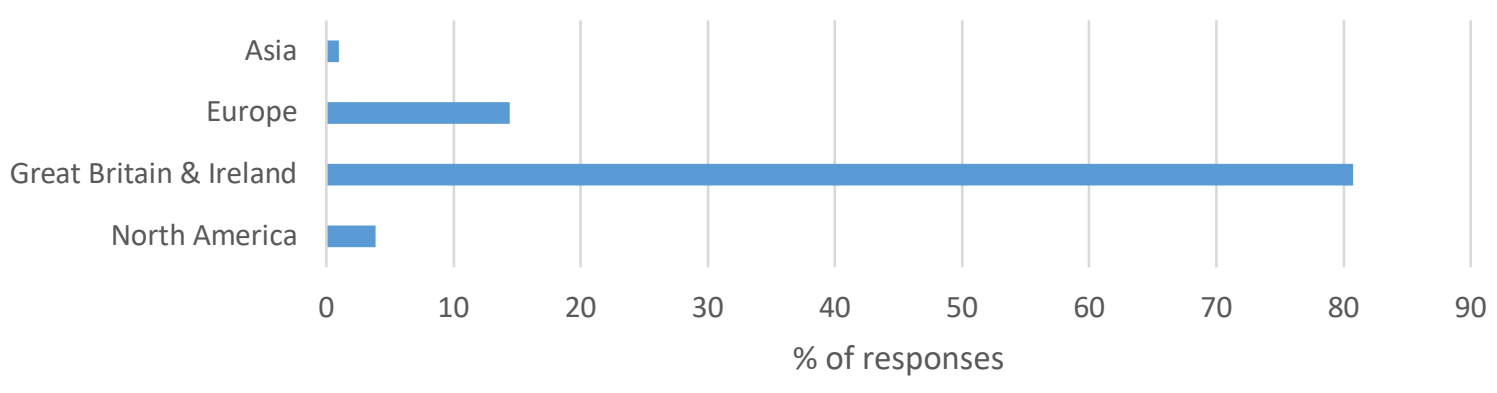




\section{Career Stage}

The VMSG community is proud to include members at all stages of their career development, both within and outside of academia. Permanent academic staff accounted for $20 \%$ of the respondents and $11 \%$ of the respondents were non-academic staff. In total $30 \%$ of respondents were students ( $2 \%$ undergraduate, $4 \%$ Masters and $24 \% \mathrm{PhD}$ student), $9 \%$ were postdoctoral researchers and $7 \%$ were retired. Multiple selections were possible and respondents could also select which careers stage they were at. From the responses, 24\% identified as Advanced academic careers whereas $21 \%$ identified as Mid academic career.

\subsection{Please select your career stage (select all that apply; 105 responses)}

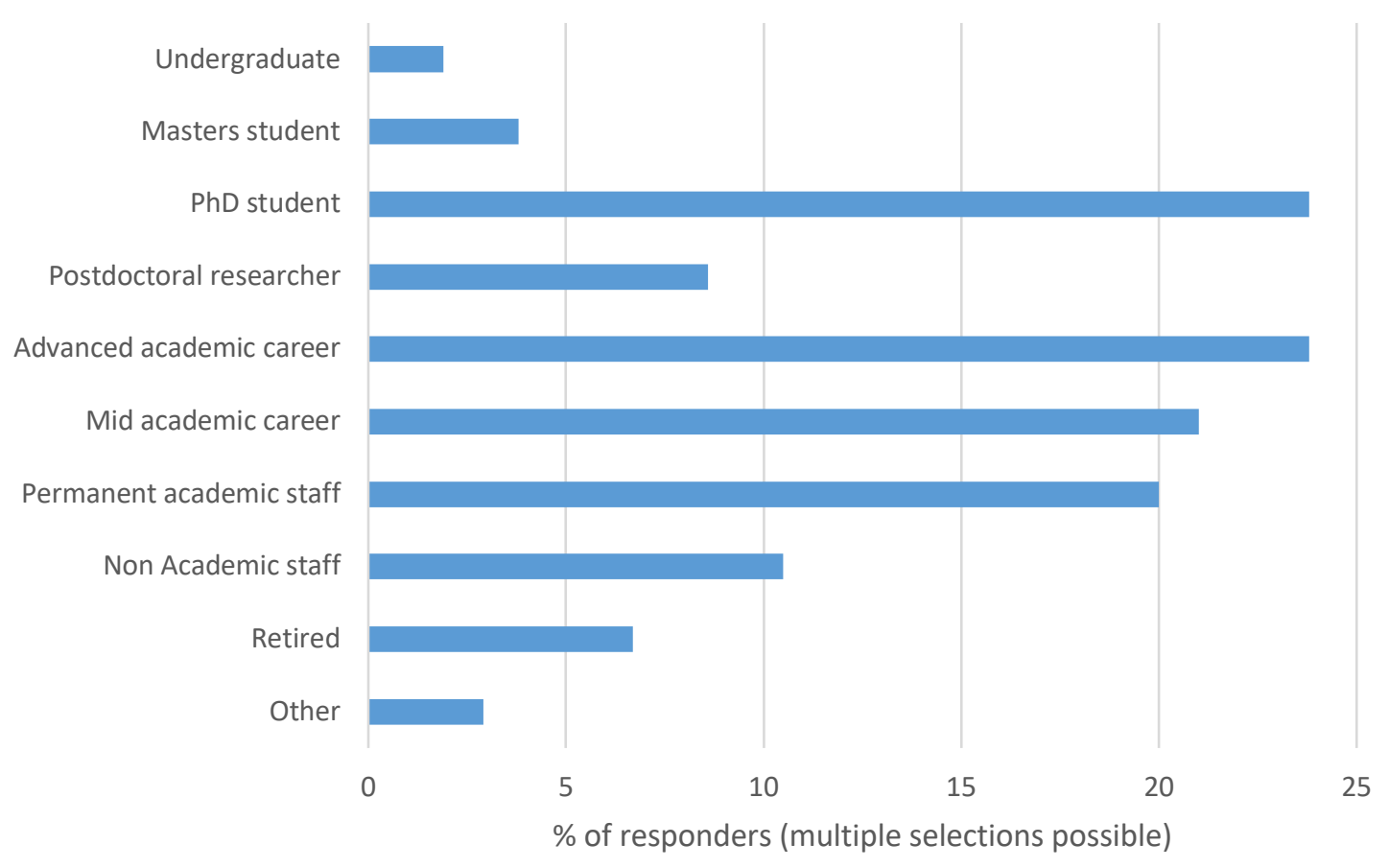

\section{Research Interests}

The remit of the VMSG includes the diverse fields of volcanology, petrology and geochemistry. More than $70 \%$ of respondents identified volcanology as a main research interest of theirs, followed by petrology and geochemistry which each were identified by more than $50 \%$ of respondents as a main research interest. Geophysics and geochronology were the next most popular research interests with $15-20 \%$ of respondents researching in each of these fields. All other research interests (including atmospheric chemistry, structural geology and tectonics, geodesy and social volcanology) were all minor research topics identified by respondents with each representing $<5 \%$ of the community. 


\subsection{What are your main research interests? (104 responses)}

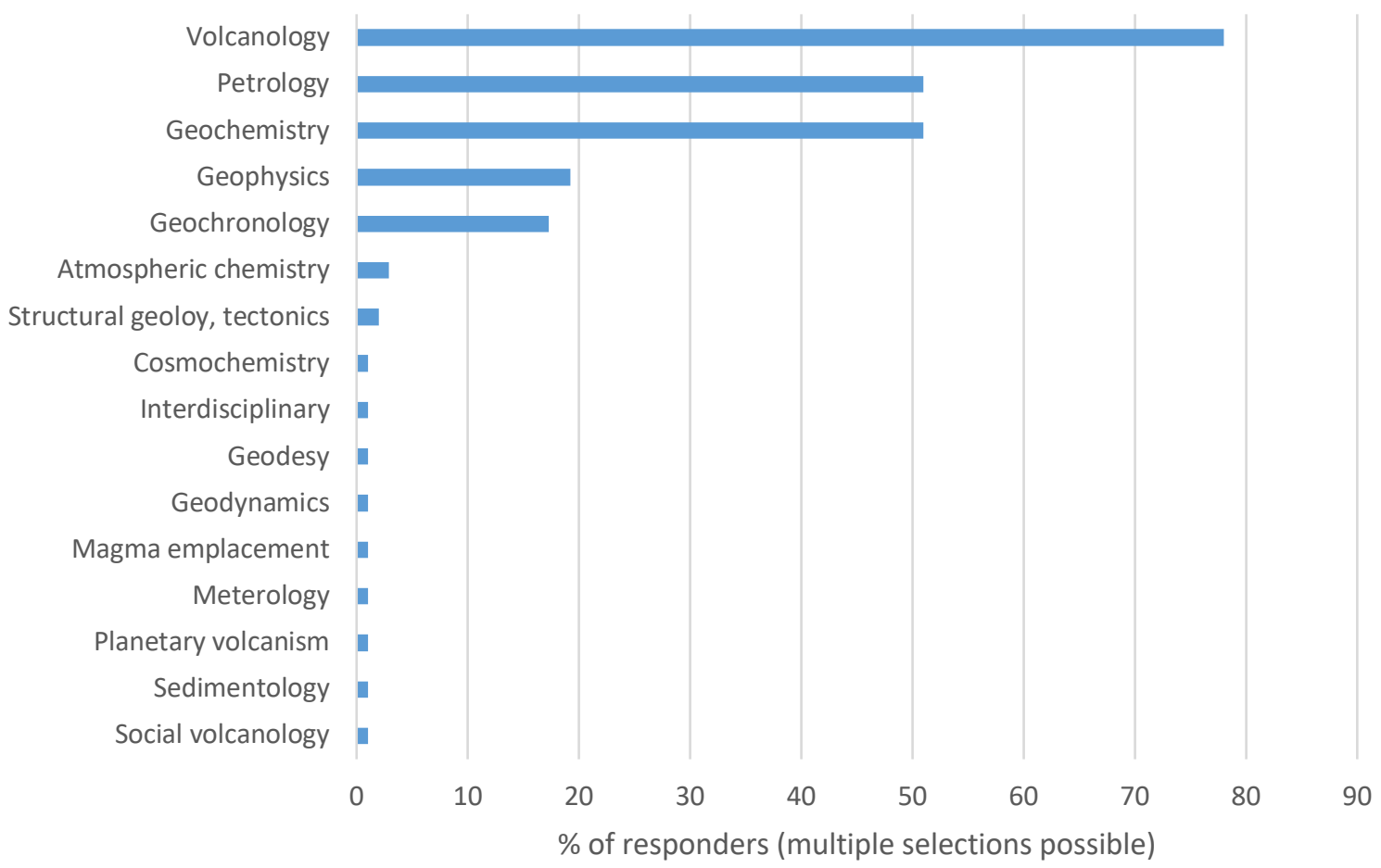

\subsection{Are you a member of any of the following professional societies?}

Our community is also diverse in their memberships of other professional societies, out of 92 responses, the largest proportion (24\%) of respondents being members of IAVCEI. This was closely followed by Mineralogical Society membership (22\%) and Geological Society of London membership (19\%).

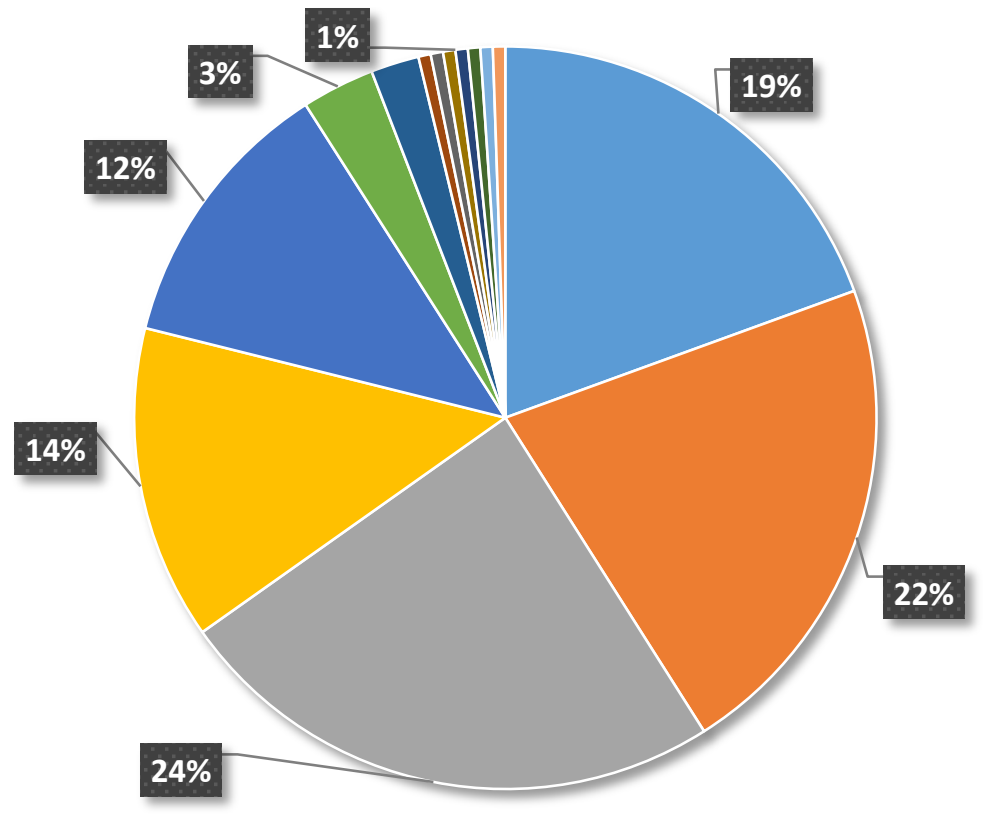

- Geol Soc of London
Min Soc
- IAVCEI
AGU
- EAG
- IUGG
- EGU
- RAS
- Remote Sensing
- Geol Soc Glasgow
- Int Ass Geoanalysts
- GA
- Min Soc America
EAGE, DGG




\section{VMSG Conferences}

4.1 Which of the following best describes your attendance at VMSG annual conferences in general (102 responses)

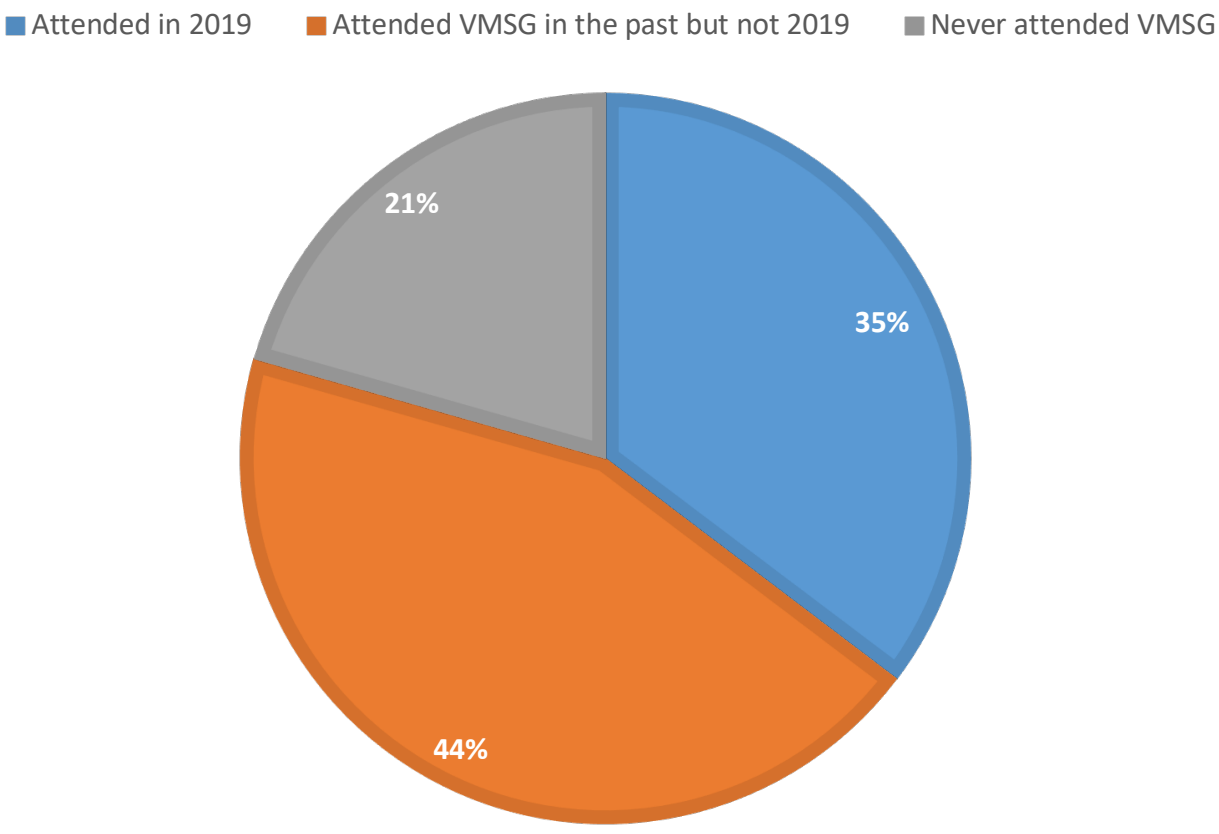

4.2 In the past 5 years how many times have you attended annual VMSG conferences? (102 responses)

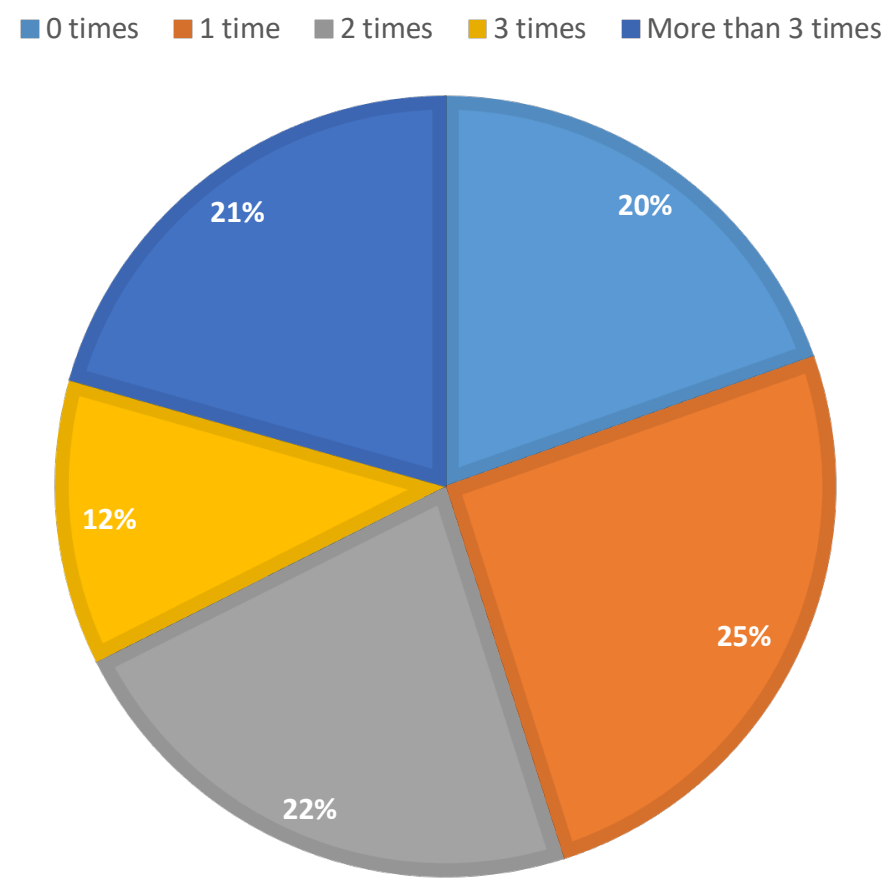


4.3 Do you consider VMSG conferences to be expensive? (94 responses)

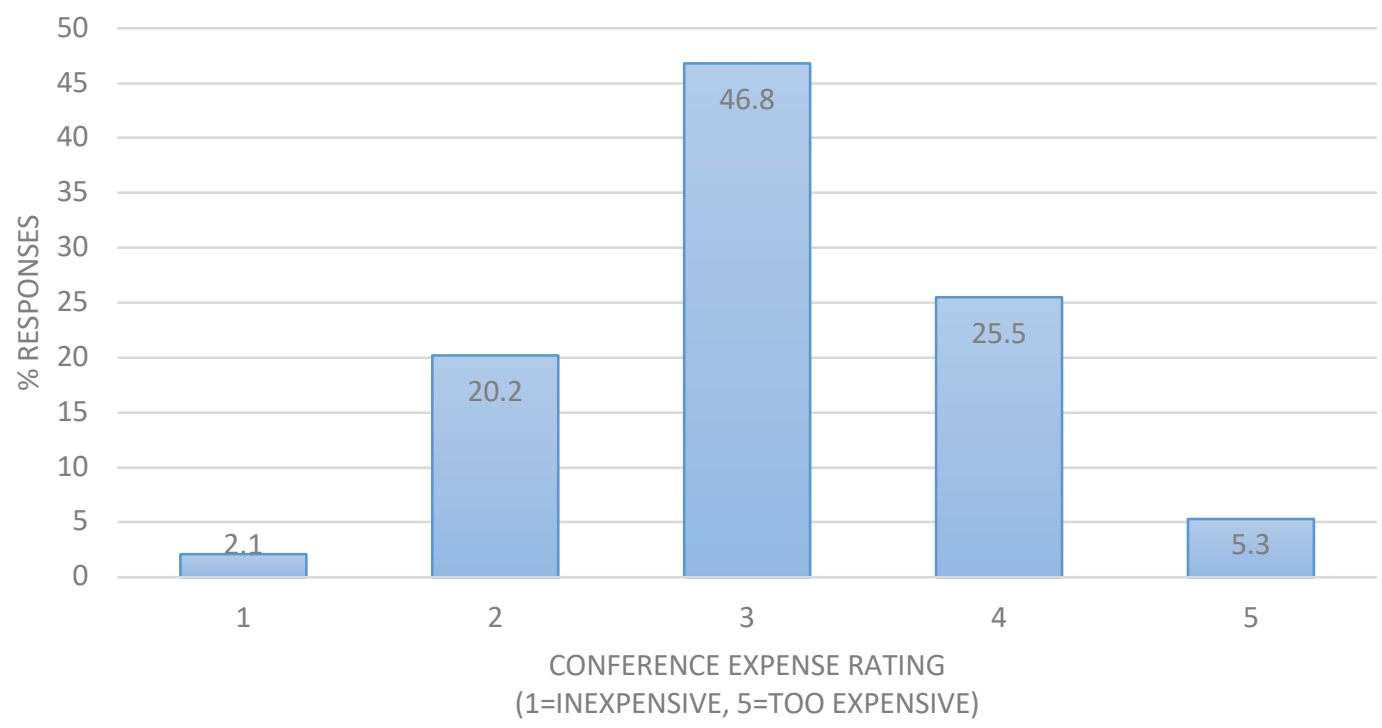

4.4 Please rate the scientific quality of the oral sessions at VMSG annual conferences (92 responses)

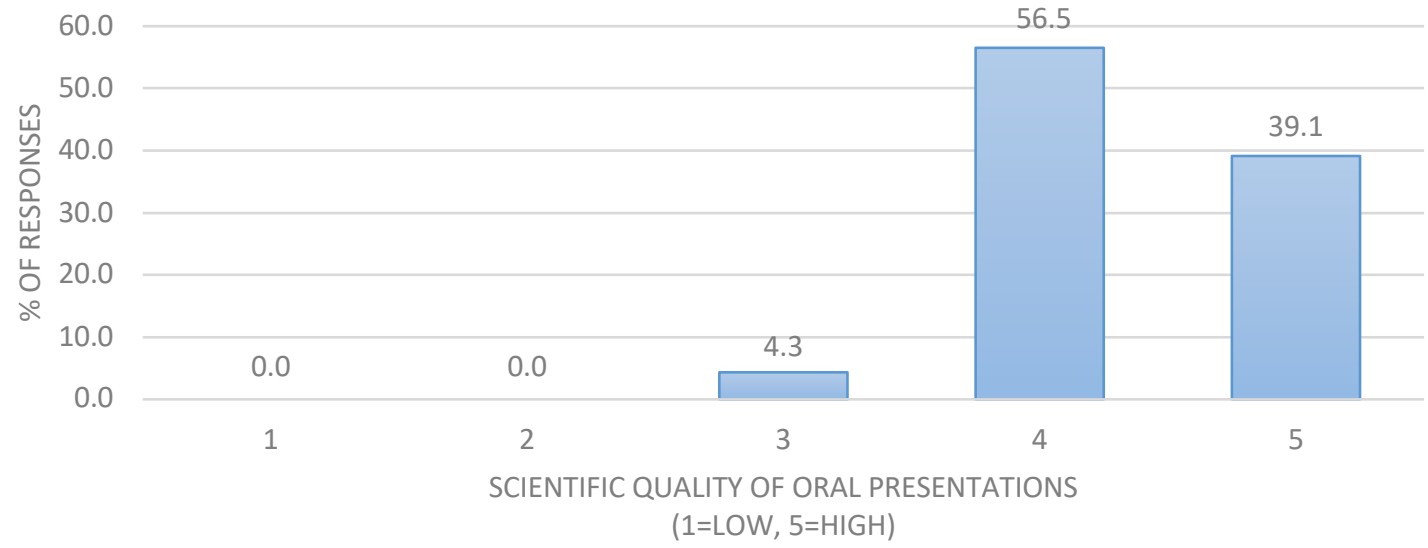

4.5 Please rate the scientific quality of the poster sessions at VMSG annual conferences (1=low, 5=high; 92 responses)

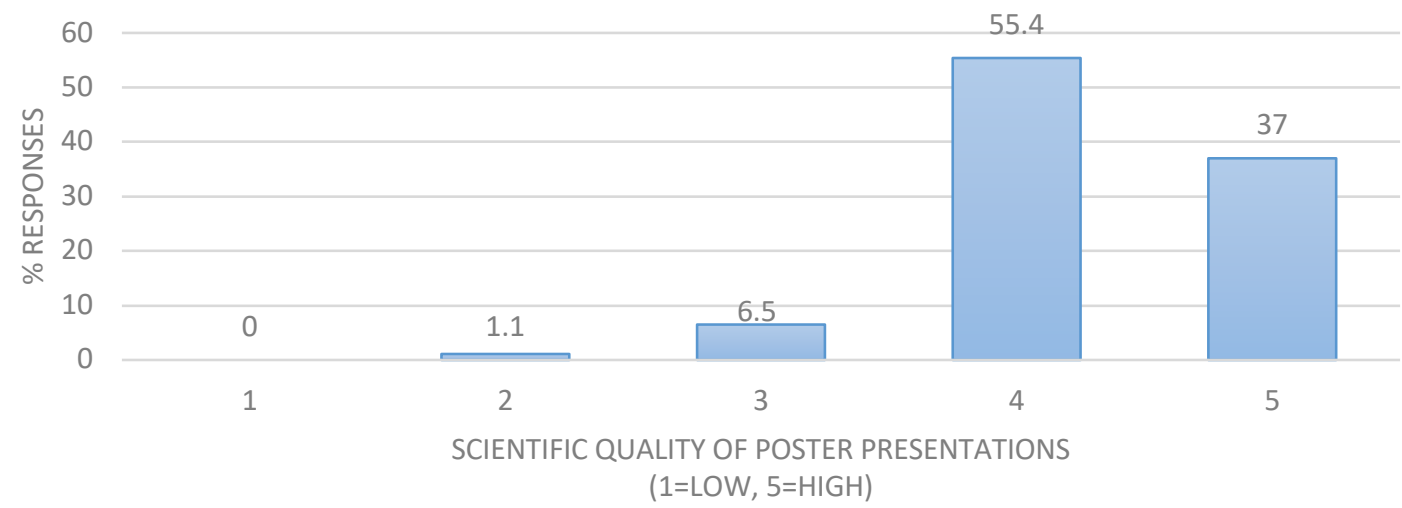




\subsection{Why do you attend VMSG conferences? (94 responses)}

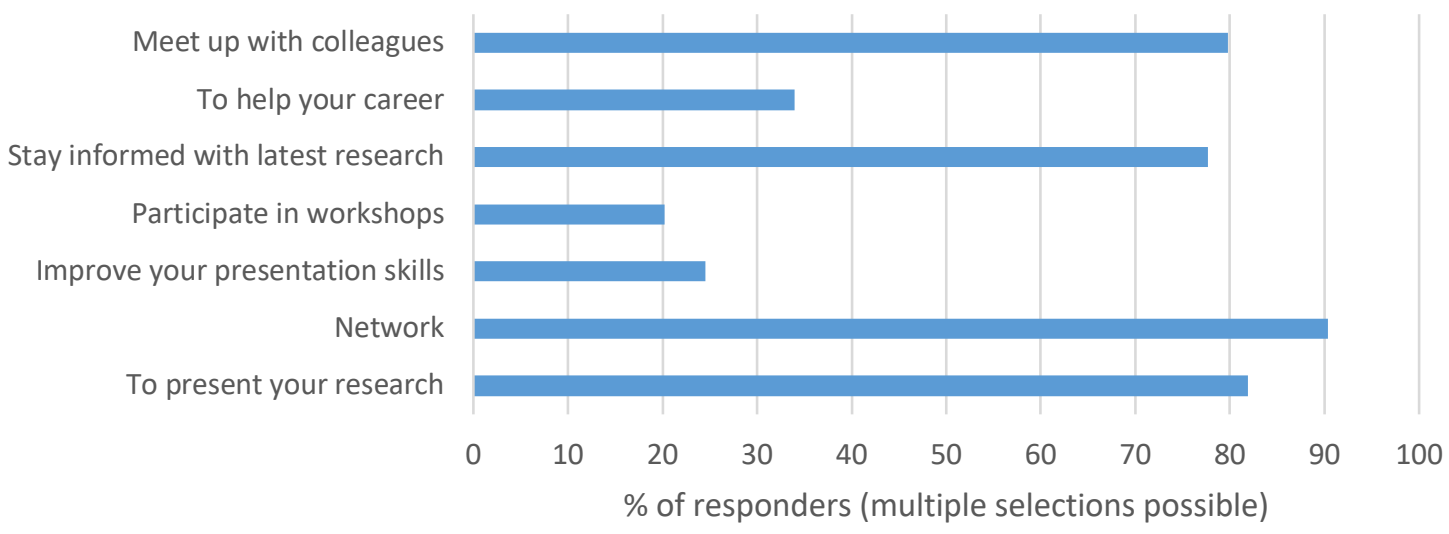

4.7 Did you present your research findings at the VMSG2020 conference in Plymouth? (102 responses)

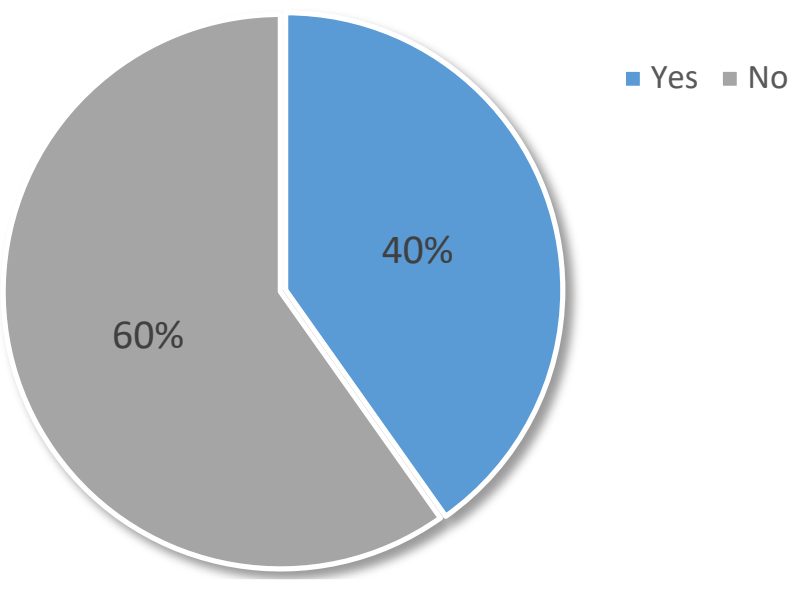

4.8 If you answered 'yes' to the above question, how did you present your research at VMSG2020? (42 responses)

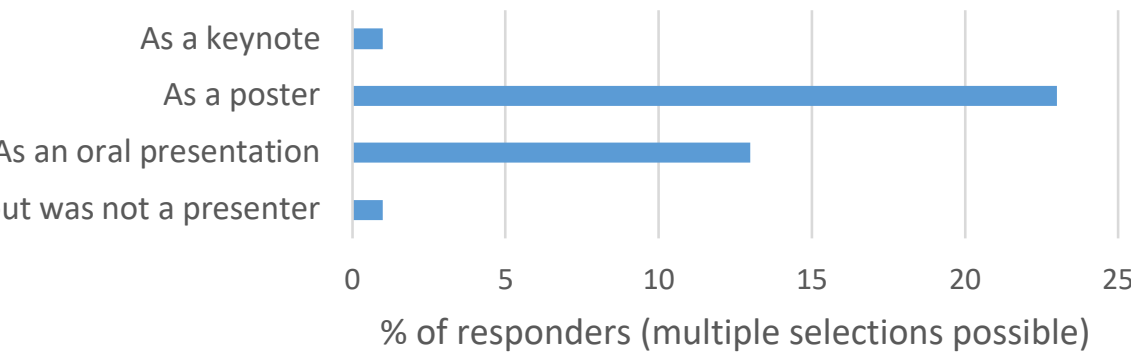

Respondents were then asked for their views on the annual VMSG conference. There were many text-based responses to this ( 46 responses received), so below is a summary of the key points raised:

- ${ }^{* *}$ Community: The annual conference is often well organised, welcoming and with a friendly atmosphere with a great community feel 
- $\quad * *$ Quality of contributions: The calibre of scientific presentations is very high, with professional and inspiring talks that are a great boost of motivation

- *Scientific discussions: The discussions held at the annual conference are always very useful

- *Student contributions: The meetings are a valuable forum for students to present research and discuss ideas, which we all benefit from

- Social events: The social events are fun, and the organisation is always great

- Networking: The annual conferences are excellent opportunities to see the breadth of research and to talk to others in the field.

- ECR opportunities: It is important that both early career and more experienced academics attend to improve the networking possibilities

- Integration into VMSG community: The conference enables those who have been away from the UK to more easily enter back into the UK volcanology community

- Internationality: The meetings are international in outlook whilst being supportive for students

- Organisation: The conferences and workshops are well organised with accurate and comprehensive information provided

Respondents were then asked how annual meetings might be improved, with the following summary of responses:

- $\quad{ }^{* *} \mathrm{It}$ is important to keep the programme varied to prevent it being too focused on one area

- *Some ECR-specific events (e.g. coffee), group chats (WhatsApp or Facebook), workshops, prizes

- When the event itself is confined to one room this makes networking with a variety of people easier

- Keep the themes/sessions short and varied and do not become too niche

- Ensure the conference moves around the UK

- Keep posters up for the whole of the conference

- Ensure the cost of annual meetings stays low, or is lowered if possible

- More joint meetings with other SIGs would be good

- Enable remote participation to be more inclusive and considerate for those who cannot afford in time or money to come to a three-day conference far from home

- More information on marking criteria for posters and talks, to help presenters improve

- Invite more keynote speakers, and advertise them better

- Introduce debate-oriented sessions

- Introduce $3 \mathrm{~min}$ oral presentations of posters

- Introduce a buddy scheme between PhDs and ECRs, and ECRs and more established academic staff

- Travel grants for non-students would be appreciated

- Increase support for postdoctoral researchers and new lecturers, particularly with financial support

- Please include more social volcanologists

- Raise awareness of professional conduct expected at these meetings and avenues for people to report harassment of any kind ("it shouldn't fall to females to warn each other of the usual suspects prior to each conference, the conference should be a safe environment for young researchers") 


\section{VMSG Workshops and Fieldtrips}

5.1 Have you ever attended a workshop organised by VMSG? (105 responses)

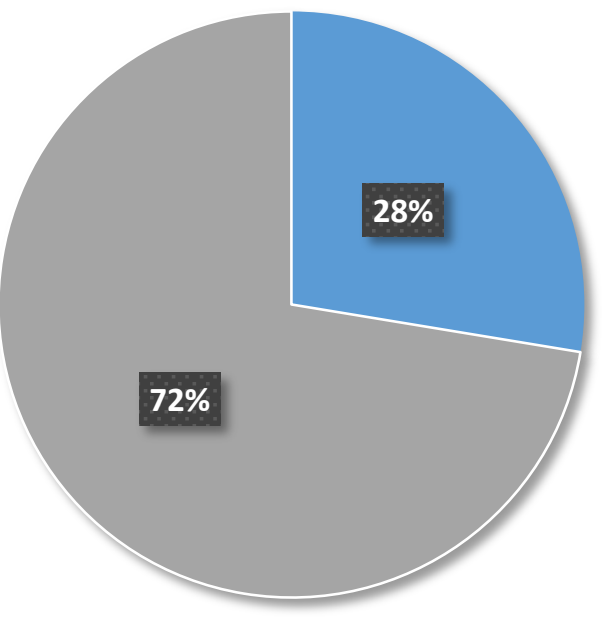

Yes

No

\section{$28 \%$}

5.2 Have you ever attended a fieldtrip organised by VMSG? (105 responses)

No

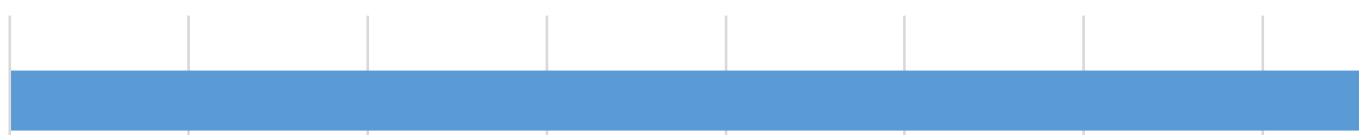

Yes

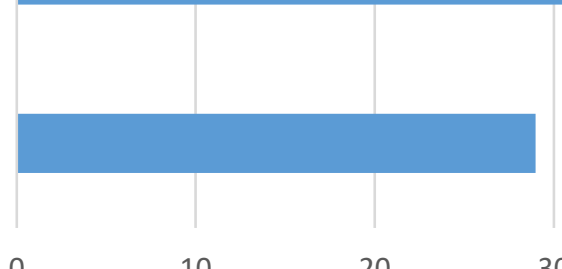

$0 \quad 10$

20

30

40

50

60

Number of responders

\subsection{If yes, when was this? (29 responses)}

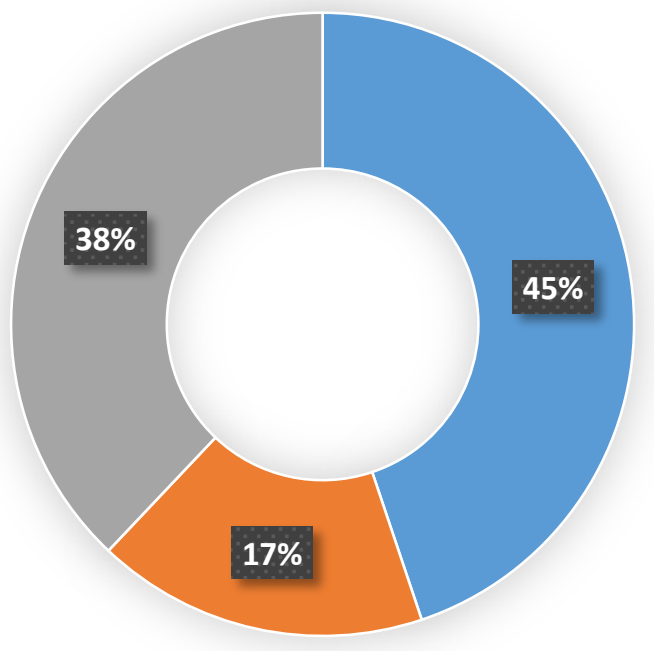

- More than 10 years ago

- In the last 5 to 10 years

- In the last 5 years 


\subsection{Have VMSG events lived up to your expectations? (93 responses)}

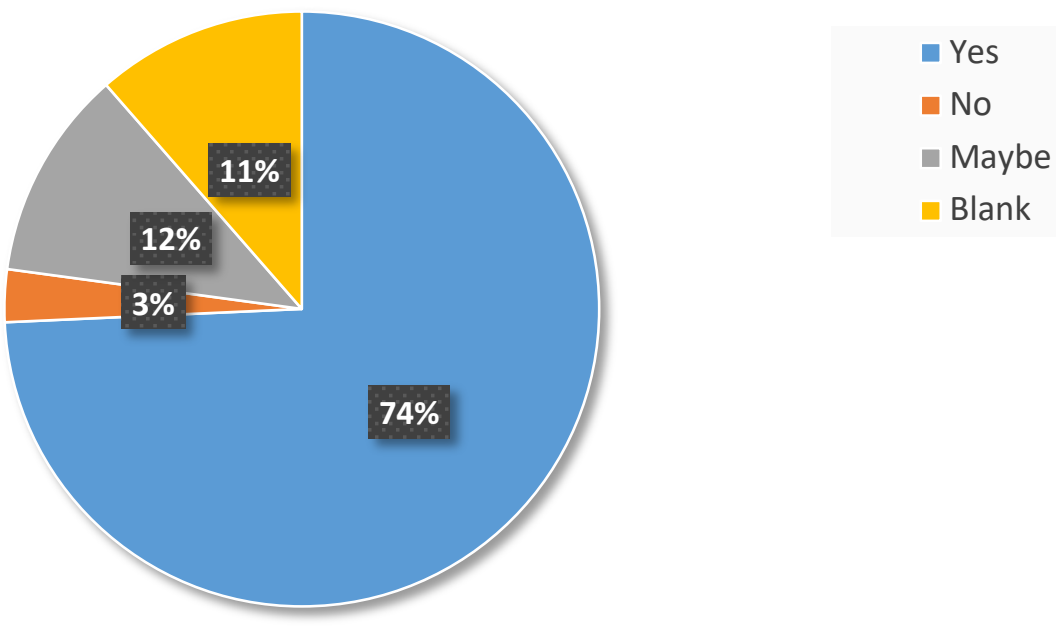

\section{VMSG Student Bursaries and Fieldwork Grants}

Twice per year VMSG offers students the opportunity to apply for a bursary of up to $f 500$ to fund their research activities. Additionally, since 2019 the VMSG has funded the 'Henry Emeleus fieldwork grant' which provides up to $\mathrm{f} 1000$ per year to support an individual's field-based research associated with the Paleogene North Atlantic Igneous Province. These funds are financed through the yearly VMSG conference.

\subsection{Have you received a student bursary? ( 24 responses)}

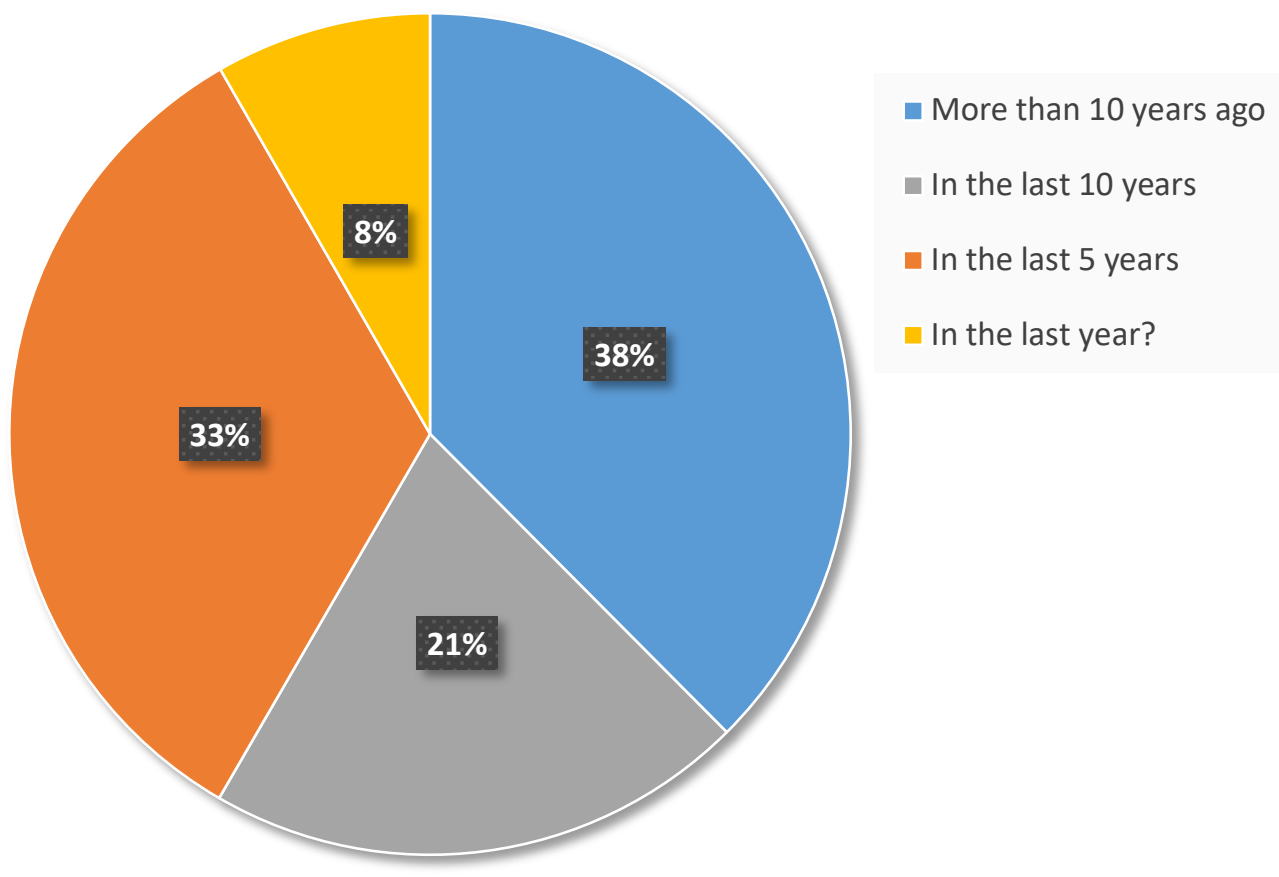




\subsection{What was this for? (24 responses)}

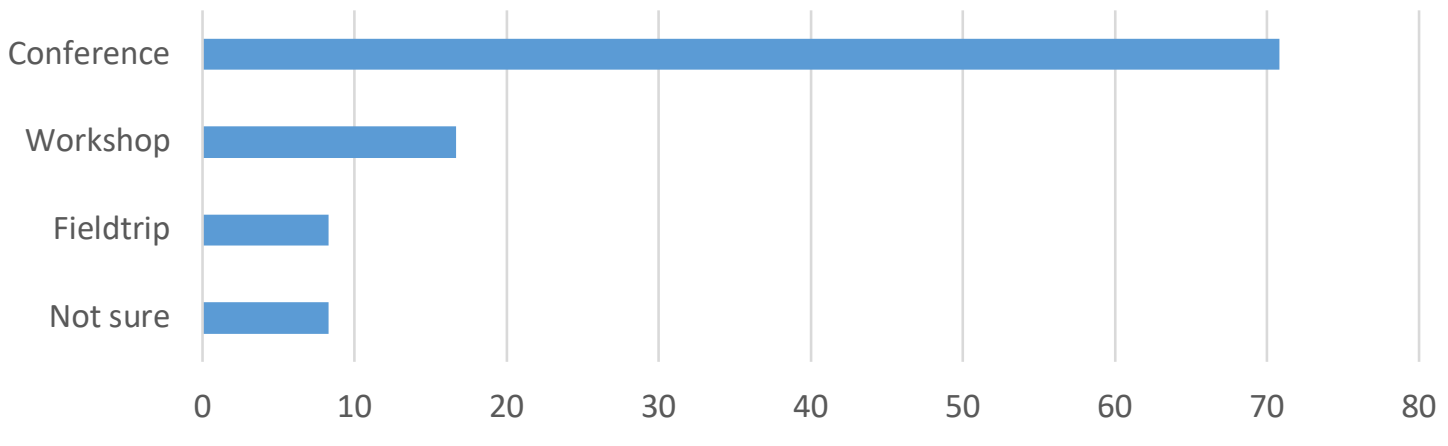

\section{VMSG Equality, Diversity \& Inclusion}

The VMSG is committed to promoting equality, diversity and inclusion in all its activities. In 2019 a dedicated VMSG committee position of 'Equality, Diversity and Inclusion Officer' was created, and in 2020 the first Equality, Diversity and Inclusion report from the VMSG committee will be published. We wanted to understand how diversity, equality and inclusivity are considered by our membership, and how they perceived the VMSG in relation to equality, diversity and inclusion. A large proportion (77\%) of the survey respondents responded stating that they thought the VMSG was "about right' in its efforts to promote equality, diversity and inclusion in the community. Out of the 95 responders, $11 \%$ felt that too little was being done and $5 \%$ selected both "Too little" and "About right", with some of these responders adding a comment that gender efforts were good but more should be done with regard to sexuality and ethnicity.

7.1 How much do you think VMSG is doing in terms of promoting equality \& diversity in the community? (95 responses)

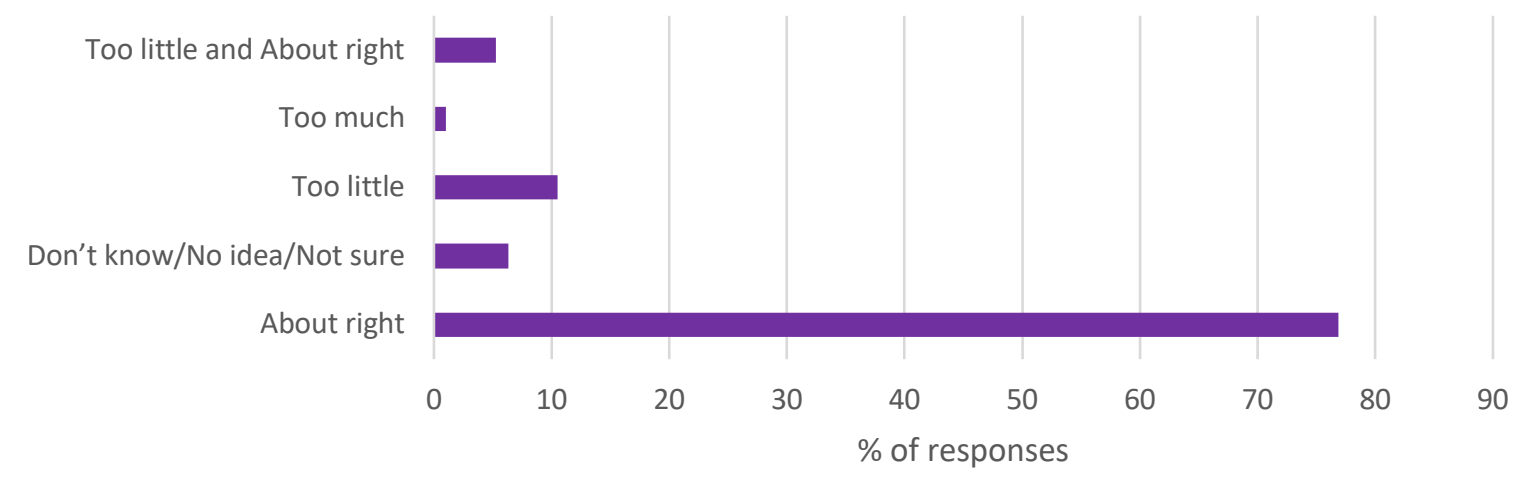

In the survey we asked the respondent for suggestions on things which VMSG might do to increase or promote equality and diversity. In total there were 31 free-text responses to this, and we have summarised the key points raised as the following:

- $\quad{ }^{* *}$ Publish equality, diversity and inclusivity data from conferences (e.g. speakers, keynotes, session chairs) including gender but also ethnic diversity, class and disability, and noting that participants should be able to define their gender if statistics on gender are to be collected and used 
- *Gender equality appears to be quite good but more needs to be done with regard to ethnic and racial diversity

- Revisit the equality and diversity statement to make it less generic

- Provide training courses related to diversity and equality, such as unconscious bias

- Investigate the provision of virtual presentation at meetings (for example to reach international audiences)

- Include talks about equality and diversity and unconscious bias in volcanology at VMSG conferences

- Investigate how to ethically collect and use data on a range of characteristics including race, faith, LGBTQ+ with respect to the VMSG community

- A fund to support the provision of fieldwork for less-able people

- Publish equality and diversity data about VMSG committee membership

- Be cautious about filling 'quotas'

- Highlight role models

- The timing of the annual meeting coincides with the start of the school year, which means parents are not able to attend

- Outreach activities for school children to attract future scientists into the field

- Provide a mentoring scheme

- Provide forums for views to be heard in an informal setting

- Consider creating an Equality and Diversity award

- Consider having a diversity and equality evening social during the annual conference

- Include more reference to hidden disabilities at conferences, perhaps with a sunflower lanyard scheme

- Use important online resources such as https://500womenscientists.org/inclusive-scientificmeetings and https://www.agu.org/Learn-About-AGU/About-AGU/Ethics/SafeAGU

- Ensure a range of non-alcoholic beverages are available at the conference and there should be a limit on alcoholic drinks to improve the ability of those who do not want to be in an alcohol-dominant environment to participate

- All gender toilets should be clearly available at VMSG conferences

- Solicit articles and opinion pieces on diversity and equality for the newsletter to reflect underrepresented voices in geosciences

- Provide stickers/badges of preferred pronouns at conferences

This is a fantastic list of suggestions from our community, and we feel it really demonstrates how important diversity and equality is to them. Several of these suggestions have already been incorporated into our recently updated 'Guidelines for the Local Organising Committee' document, which we provide to each host institution of our annual conference, and we have recently updated our 'Code of Conduct for VMSG meetings' (https://vmsg.org.uk/events/code-of-conduct-formeetings/) to better reflect the values of the VMSG community. We will also shortly publish our first 'Equality, diversity and inclusion report' which will include a list of recommendations for the future improvement of diversity and equality in the VMSG. 


\section{VMSG \& the Environment}

VMSG takes its environmental impact seriously, and we were interested in how this reflects the views of our community. We were also interested in their thoughts on what the future environmental priorities of VMSG should be. The respondents were very much in favour of VMSG playing an active role in managing the carbon contribution from its activities with $86 \%$ in agreement. The most popular response related to 'Helping to promote environmentally-responsible behaviours in academia' with $90 \%$ of respondents supporting this. This was followed by 'Encourage remote participation to meetings and conferences' (72\%) and 'Carbon-offsetting the annual conference' (59\%). Interestingly, 'promoting waste minimalisation' and 'promoting car share and public transport' were generally not supported with only $1 \%$ of respondents selecting these otions.

\subsection{Would you like VMSG to play an active role in managing the carbon contribution from its activities? (99 responses)}

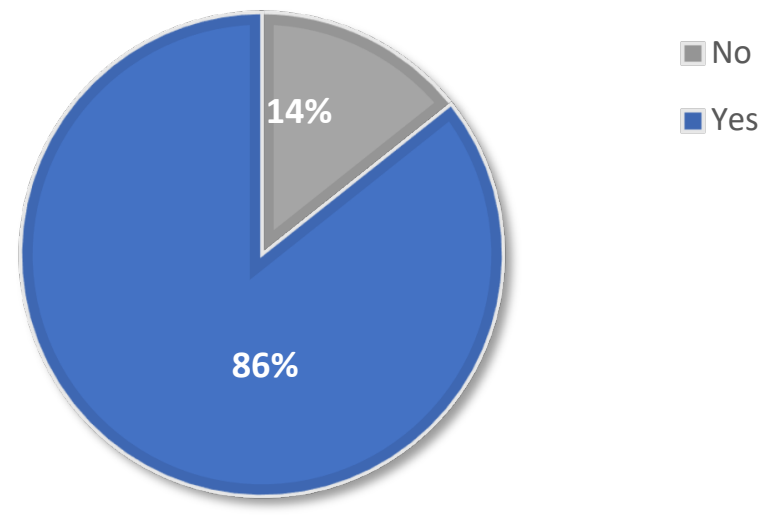

\subsection{If yes, how? Tick any of the following that apply (93 responses)}

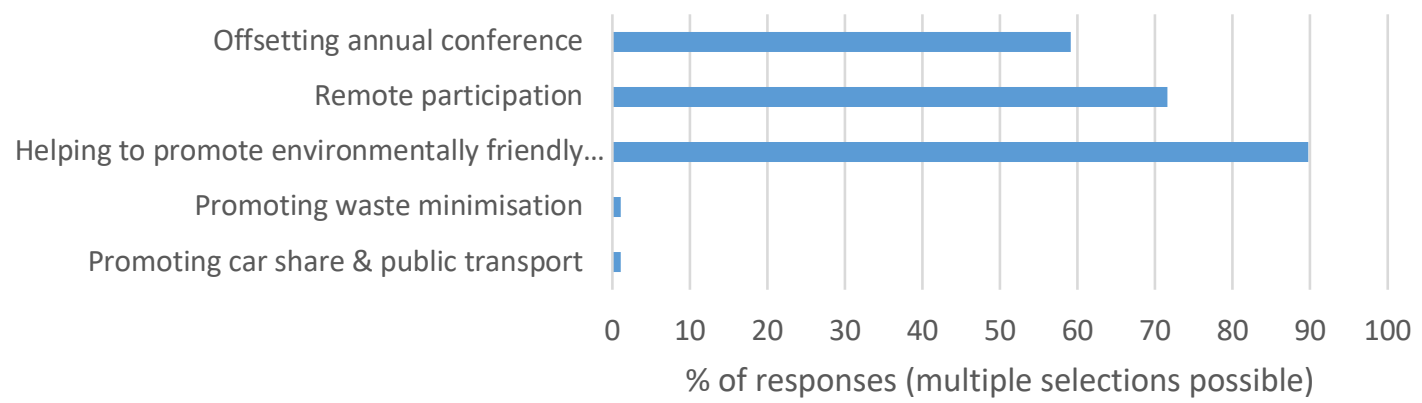

The respondents were asked for their suggestions related to reducing the environmental impact of the VMSG, with the following suggestions made ( 6 responses):

- *Arrange to have the annual conference streamed online so that people can choose to attend but not travel long distances

- Promoting minimal plastic use in advance of attending the annual conference, e.g. bring your Keepcup, get the bus, and don't use single-use

- Each year, a monetary contribution for carbon offsetting should be made

- Better communicate what rock samples are held in the UK, to help avoid unnecessary fieldwork

- Advertise when international visiors are in the UK to help reduce the need for repeat visits 


\section{VMSG Communications \& Making VMSG Work for you}

9.1 How do you receive information about VMSG activities? (105 responses)

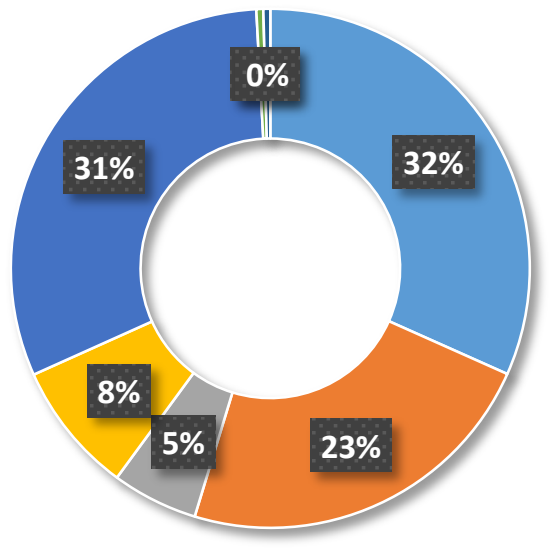

- Newsletter

- Twitter

- From a colleague

Word of mouth

- Email

- Facebook

- Website

9.2 What information would you like to receive via social media? (87 responses)

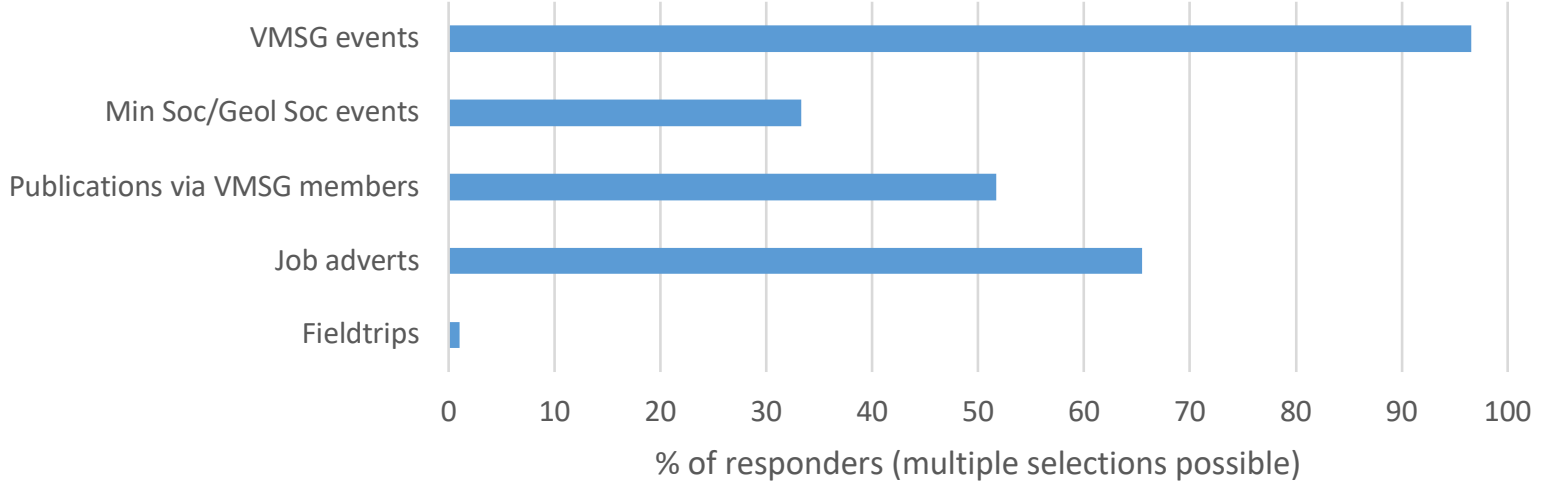

9.3 Do you use VMSG to publicise any of the following? (44 responses)

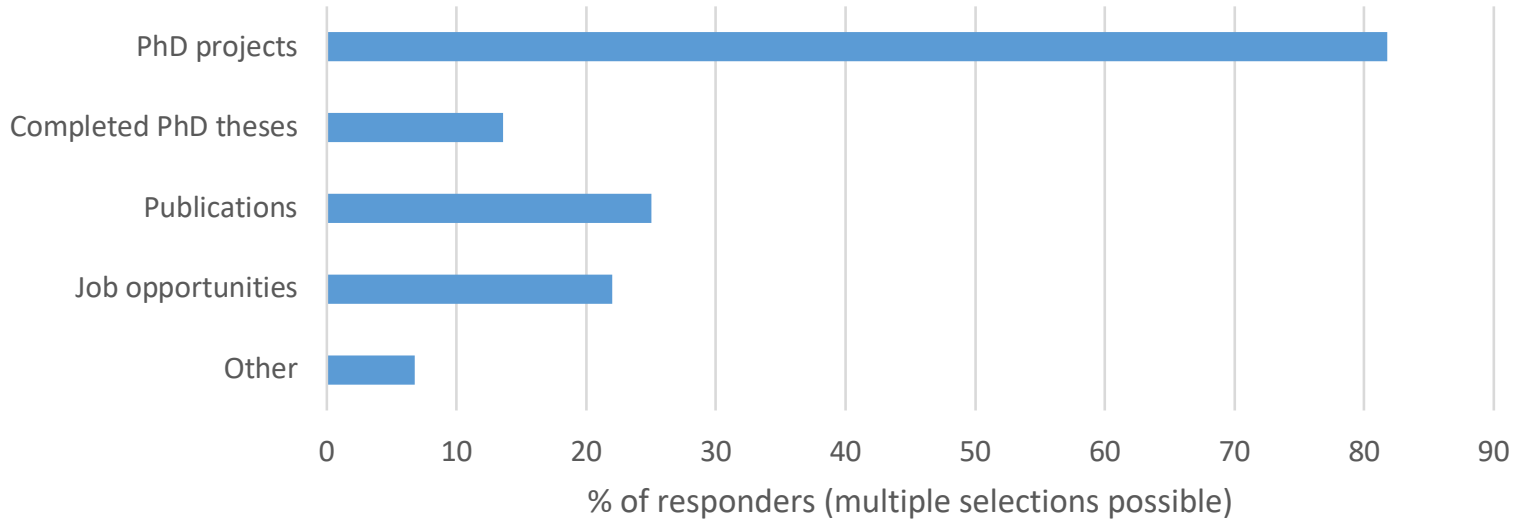




\section{Summary \& Conclusions}

The VMSG2020 survey results indicate that our community is diverse in terms of gender, sexual orientation and place of residence. However, important information regarding characteristics such as ethnic background, class and disability are still not known. This information should be collected in future VMSG surveys, but also at annual conferences, workshops, fieldtrips and supported events. This data is essential for improving our understanding of the VMSG community and ensuring that views from all groups are represented and supported. To emphasize our commitment, the VMSG Committee now has a dedicated officer for Equality and Diversity.

The VMSG community is also diverse in terms of career stage, with Advanced academics and PhD students accounting for nearly $50 \%$ of the community collectively. The community also includes a significant proportion of professionals outside of academia. Early Career Researchers have also been identified as a relatively under-supported group and we are actively working to ensure that this is addressed, e.g. by having ECR forums and an ECR rep on the VMSG Committee.

The main VMSG activities include its annual conference, workshops and fieldtrips, and all these activities are very popular with those who attend, with high quality science at the heart of the contributions. We seek to celebrate the scientific achievements and contributions of our community via a series of annual awards and prizes.

Our members have indicated overwhelmingly that they would like VMSG to improve the environmental impact of its activities, with the provision of online presentations of conference contributions being suggested by many.

Some members raised the possibility to become more engaged with other Special Interest Groups, and the potential to become aligned with other organisations such as the Royal Astronomical Society. They also suggested increased support of local meetings throughout the year.

There are several action and discussion points raised in this survey which warrant additional discussion within the VMSG community, and externally with our overarching organisations. A particular focus for the coming months should be advertising the new 'Code of Conduct for VMSG meetings' and the publication of the first 'VMSG Equality, Diversity and Inclusion Report'.

\section{Acknowledgements}

We would like to thank all members of the VMSG community who participated in the survey. We also express our gratitude to all members of the VMSG Committee who provided very helpful feedback on this report.

\section{Cover Image}

Kīpuka in a recent lava at James Bay, Isla Santiago, Galápagos (C SA Gibson). A location that inspired Charles Darwin's work on volcanoes: DARWIN, C. 1844. Geological Observations on the Volcanic Islands, Visited during the Voyage of H. M. S. Beagle, Smith, Elder and Co., London, England. 175 pp.

\section{Contact details and Preprint}

For any questions about this report, please contact the VMSG Secretary Dr. Janine Kavanagh (Janine.Kavanagh@liverpool.ac.uk) or VMSG Chair Prof. Sally Gibson (sally@esc.cam.ac.uk).

This document is a preprint submitted to EarthArXiv. The final version of the report will be published on the Volcanic and Magmatic Studies Group website (https://vmsg.org.uk). 